\title{
Evaluation of laser cleaning for the restoration of tarnished silver artifacts
}

T. Palomar ${ }^{1,2 *}$, M. Oujja ${ }^{3}$, I. Llorente ${ }^{1}$, B. Ramírez Barat ${ }^{1}$, M.V. Cañamares ${ }^{4}$, E. Cano ${ }^{1}$, M. Castillejo ${ }^{3}$

${ }^{1}$ Centro Nacional de Investigaciones Metalúrgicas (CENIM-CSIC), Avda. Gregorio del Amo 8, 28040 Madrid, Spain

${ }^{2}$ Depto. de Conservação e Restauro and Research Unit VICARTE-Vidro e Cerâmica para as Artes, Campus de Caparica, FCT-UNL, Quinta da Torre, 2829-516 Caparica, Portugal

${ }^{3}$ Instituto de Química Física Rocasolano (IQFR-CSIC), Serrano 119, 28006 Madrid, Spain

${ }^{4}$ Instituto de Estructura de la Materia (IEM-CSIC), Serrano 121, 28006 Madrid, Spain

*Corresponding author. E-mail: t.palomar@csic.es

\begin{abstract}
In this study we evaluate the laser cleaning of tarnished pure and sterling silver substrates using a nanosecond Q-switched Nd:YAG laser at 1064, 532 and $266 \mathrm{~nm}$. To assess the effects associated with cyclic laser cleaning treatments, several cycles of tarnishing followed by laser cleaning were applied on silver coupons that were characterized by gravimetry, colorimetry, scanning electron microscopy, X-ray photoelectron spectroscopy and micro-Raman spectroscopy. According to the obtained results, none of the three wavelengths is recommended for laser cleaning of pure silver objects, while for sterling silver artifacts, the visible laser wavelength of $532 \mathrm{~nm}$ seems the most appropriate.
\end{abstract}

(C) 2016. This manuscript version is made available under the CC-BY-NC-ND 4.0 license http://creativecommons.org/licenses/by-nc-nd/4.0/

Published in Applied Surface Science (2016) 387, 118-127

https://doi.org/10.1016/j.apsusc.2016.06.017 


\section{Highlights}

- Cyclic application of Q-switched Nd:YAG laser cleaning induces irreversible changes on pure silver.

- Laser cleaning using Q-switched Nd:YAG laser at $1064 \mathrm{~nm}$ induces loss of material and color changes.

- Laser cleaning using Q-switched Nd:YAG laser at $532 \mathrm{~nm}$ seems the most appropriate for cleaning sterling silver objects.

Keywords: Laser cleaning, Silver, Sterling silver, Tarnishing, Cultural Heritage. 


\section{Introduction}

Historical artifacts located in museums and private collections are exposed to different atmospheres (exhibition halls, showcases, storage, packaging, etc.) which can contain various degradation agents that threaten their preservation. For metallic objects, corrosion is the main degradation phenomenon, caused by reaction of the metal with environmental humidity and pollutants, such as $\mathrm{SO}_{2}, \mathrm{NO}_{\mathrm{x}}, \mathrm{O}_{3}$, reduced sulfur compounds $\left(\mathrm{H}_{2} \mathrm{~S}, \mathrm{OCS}\right)$ and volatile organic compounds (VOC) [1-3].

Tarnishing (the formation of a thin colored corrosion layer) is the most common alteration mechanism of silver objects. It is produced by reduced sulfur gases, principally $\mathrm{H}_{2} \mathrm{~S}$, and other organic molecules from atmospheric pollution, such as carbonyl sulfide (OCS) and dimethyldisulfide $\left(\left(\mathrm{CH}_{3}\right)_{2} \mathrm{~S}_{2}\right)$ [4-8]. Tarnishing is originated in the first stage by the reaction of the environmental oxygen with the silver surface forming a thin oxide film. Then, the presence of reduced sulfur species in the atmosphere can displace these oxides leading to the formation of silver sulfide $\left(\mathrm{Ag}_{2} \mathrm{~S}\right)$. Humidity, $\mathrm{NO}_{2}$, ozone and ultraviolet radiation can act as accelerators of the process [7, 9]. Relevant chemical reactions involved in the tarnishing mechanism are:

$$
\begin{aligned}
& 2 \mathrm{Ag}+\mathrm{H}_{2} \mathrm{~S}+1 / 2 \mathrm{O}_{2} \rightarrow \mathrm{Ag}_{2} \mathrm{~S}+\mathrm{H}_{2} \mathrm{O} \\
& 2 \mathrm{Ag}+\mathrm{OCS} \rightarrow \mathrm{Ag}_{2} \mathrm{~S}+\mathrm{CO}
\end{aligned}
$$

$\mathrm{Ag}_{2} \mathrm{~S}$ is a black compound and its formation on the silver surface produces a loss of the shine and a change of color to a dark appearance, what is unacceptable for an historic artifact [7]. Restoration treatments are applied to clean tarnished silver objects and to recover their original shiny metallic appearance. The cleaning procedures most frequently applied on historical silver objects are of mechanical, chemical and electrochemical nature [7]. Mechanical methods, mainly applied by using hand tools and abrasives, are the most frequent cleaning procedures, nevertheless they produce localized and uncontrolled mass loss leading to a fast re-tarnishing process [10-12]. Chemical cleaning methods are less frequently used, although commercial products or thiourea acid solutions have been employed due to their fast cleaning effects. Thiourea acts as a fast chelating agent dissolving the tarnish layer. However this effect is not easily controlled and usually leave a completely heterogeneous surface which could retain residues from the cleaning solution $[12,13]$.

Recently, lasers have been used for the removal of different corrosion layers, encrustations, and coatings on archaeological and historical metal objects [14-25]. The 
application of lasers in conservation faces the challenge to deal with some issues, among others the preservation of the original surface and the formation of unwanted laser induced alteration layers [26, 27]. Most of the previous studies have been focused on the laser irradiation effects, using different wavelengths and pulse duration, on the corrosion layer and on the underlying material after a single laser treatment [28-34]. However, the effects associated with successive laser cleaning treatments on tarnished silver objects have not been addressed before. Real artifacts in museums and collections are repeatedly subjected to these cycles of natural tarnishing and cleaning treatments, so the study of the cumulative effect of any treatment is highly relevant for the long term preservation of these heritage substrates.

The aim of this study is to evaluate the effect of laser irradiation using nanosecond pulses of three different wavelengths at 1064, 532 and $266 \mathrm{~nm}$ on artificially tarnished pure and sterling silver coupons with the objective of determining the optimal laser conditions for the removal of the tarnish layers in a controlled manner and with the minimum damage to the underlying silver substrates. Sterling silver was studied as representative of a typical alloy used in historical silver objects. The most important aspect of the work presented here involves the evaluation of laser cleaning effects associated with cyclic tarnishing-laser cleaning treatments, by applying different cycles of artificial tarnishing followed by laser cleaning of the considered samples. As mentioned, the literature concerning this issue is quite scarce or non-existent. The laser-induced physical and chemical modifications on tarnished silver substrates were assessed using different techniques. Surface morphology and color variations were evaluated using scanning electron microscopy (SEM) and colorimetry, and chemical composition using microRaman spectroscopy and X-ray photoelectron spectroscopy (XPS).

\section{Experimental}

\subsection{Samples}

Coupons $\left(2.0 \times 1.0 \times 0.1 \mathrm{~cm}^{3}\right)$ of pure silver $(99.50 \mathrm{wt} \%$ of silver, $0.30 \mathrm{wt} \%$ of iron, 0.13 wt $\%$ of chromium, $430 \mathrm{ppm}$ of copper, $216 \mathrm{ppm}$ of sulfur) and sterling silver (92.47 wt $\%$ of silver, $7.28 \mathrm{wt} \%$ of copper, $0.26 \mathrm{wt} \%$ of palladium), purchased from SEMPSA JP, were used as substrates. Their composition was analyzed by wavelength dispersive X-ray fluorescence (WDXRF) with a Bruker S8 Tiger system. The samples were abraded with emery paper, down to grade 2000, and washed with ethanol in an ultrasonic bath for five minutes. Tarnishing was carried out by exposure of the coupons for 72 hours to a sulfur 
vapor environment according to the thioacetamide corrosion test (TAA Test) at $22{ }^{\circ} \mathrm{C}$ [35]. The tarnish layer over the silver and sterling silver coupons presented a thickness up to $300 \mathrm{~nm}$ according to measurements carried out using SEM in cross-section preparations.

\subsection{Laser irradiation}

Laser cleaning tests were performed with a Q-switched (QS) Nd:YAG laser system (Quantel Brilliant B) that delivers pulses, at the fundamental wavelength of $1064 \mathrm{~nm}$ and its second and fourth harmonics at 532 and 266 nm, of $5 \mathrm{~ns}$ (Full Width at Half Maximum - FWHM) at a maximum repetition rate of $10 \mathrm{~Hz}$. The laser beam profile is Gaussian with a spot size diameter of $9 \mathrm{~mm}$.

The fluence (energy per unit of surface) ablation thresholds at the different considered laser wavelengths were determined by identifying the energy at which damage (discoloration and/or material removal) is observed in the sample by inspection under the optical microscope after irradiation in air. The beam size considered for such calculations was determined by measuring the area of the print left on an unplasticized polyvinyl chloride (UPVC) sheet in a single pulse. The irradiations tests at 1064 and $532 \mathrm{~nm}$ were carried out through a rectangular mask of $4 \times 6 \mathrm{~mm}^{2}$ without focusing. However, at 266 $\mathrm{nm}$ a cylindrical lens with a focal length of $150 \mathrm{~mm}$ was used to achieve a rectangular area of $2 \times 6 \mathrm{~mm}^{2}$ on the sample surface. Various conditions of energy per pulse were used. The pulse energy was measured by a power-meter (Gentec ED-200) and modified with a high energy variable dielectric attenuator (LaserOptik). Once the discoloration/ablation fluence thresholds were determined for each system (both for the silver based metals and for tarnish layers), irradiated zones were prepared with fluence values in between the ablation threshold of the base metal and that of the tarnish layer. The changes generated on the tarnish layers can be due both to ablation processes and/or local annealing and melting of the tarnish layers [24].

Table 1 shows the alteration/ablation fluence thresholds of tarnish layers and of pure and sterling silver coupons, together with the fluences used for the cleaning tests. These values are in the same range than those measured by A. Lorusso et al. and A. Buccolieri et al. in references [26,33], using pulses of $30 \mathrm{~ns}$ at $248 \mathrm{~nm}$. 
Table 1. Alteration/ablation thresholds of tarnish layers and, bare pure and sterling silver coupons, together with the fluences used for the cleaning tests in $\mathrm{mJ} \mathrm{cm}^{-2}$. Estimated errors are $10 \%$.

\begin{tabular}{lrrrrrr}
\hline & \multicolumn{3}{c}{ Pure silver } & \multicolumn{4}{c}{ Sterling silver } \\
\hline$\lambda(\mathrm{nm})$ & 1064 & 532 & 266 & 1064 & 532 & 266 \\
Ablation threshold $\left(\mathrm{mJcm}^{-2}\right)$ & 600 & 354 & 117 & 291 & 180 & 67 \\
Ablation threshold of tarnish layer $\left(\mathrm{mJcm}^{-2}\right)$ & 240 & 180 & 55 & 120 & 42 & 17 \\
Laser cleaning fluence $\left(\mathrm{mJcm}^{-2}\right)$ & 292 & 208 & 85 & 208 & 63 & 38 \\
\hline
\end{tabular}

For irradiation of the samples, the laser beam impinged perpendicularly onto the target surface which was placed on a motorized $\mathrm{XYZ}$ translation stage, where the $\mathrm{Z}$ axis is perpendicular to the sample surface. For irradiation at 1064 and $532 \mathrm{~nm}$, the unfocused beam was directed onto the surface of the sample by the help of mirrors. At these two wavelengths, the pulses have enough energy to reach the required fluence for processing the considered samples. Irradiation was performed through a rectangular mask $(4 \times 6$ $\mathrm{mm}^{2}$ ), placed on the surface of the sample, to select the central part of the laser beam and by moving the sample along the direction of the smallest mask dimension. The scanning speed, and consequently the spatial overlap of successive pulses, was chosen to ensure the delivery of approximately 100 pulses on each point of the sample. After processing a rectangular area corresponding to the half area of the sample, this was moved in the transverse direction by steps of $5 \mathrm{~mm}$, resulting in an overlap of $17 \%$ with the previous processed area. To irradiate the whole sample, this operation was done on the two faces. For irradiation at $266 \mathrm{~nm}$, the laser beam had to be focused to overcome the ablation thresholds for the corresponding tarnish layer. To that purpose, a cylindrical lens of 150 $\mathrm{mm}$ focal length was used to focus the beam down to $2 \times 6 \mathrm{~mm}^{2}$. Again in this case, the whole surface of the sample was homogeneously irradiated by moving it along the smaller dimension of the laser spot. The chosen speed sample movement ensured irradiation at this wavelength with 100 pulses on each point of the sample surface.

\subsection{Characterization techniques}

Pure and sterling silver coupons were characterized before and after laser processing by different techniques such as gravimetry, colorimetry, scanning electron microscopy (SEM), X-ray photoelectron spectroscopy (XPS) and micro-Raman spectroscopy.

The mass variation was evaluated using a Mettler Toledo AT261 Delta Range Analytical Balance. Silver based coupons were weighed after each laser cleaning cycle to determine the mass loss. It was noted that the mass increase due to the tarnishing treatment could not be measured because it was lower than the resolution of the balance. A Konica 
Minolta Portable spectrophotometer model 2500D, equipped with a mask of $8 \mathrm{~mm}$ of diameter, D65 illuminant (which corresponds to the average noon daylight from the northern sky [36]) and at 10 degrees observer, served to measure the chromatic properties of the samples and specifically the changes induced by laser irradiation. Two spectra were acquired on each side of the coupon and averaged to obtain one data point with the chromatic information. The CIE-L*a*b* color space served to determine color shifts expressed in three coordinates. The chromatic coordinates $a^{*}$ and $b^{*}$ denote the red/green value (positive values shift to red, negative values shift to green), and the yellow/blue value (positive values shift to yellow, negative values shift to blue) respectively [37, 38]. The variation of chromatic coordinates after the tarnishing-laser cleaning treatments, $\Delta a^{*}$ and $\Delta b^{*}$, was evaluated by:

$$
\begin{aligned}
& \Delta a^{*}=a^{*} \text { clean silver }-a^{*} \text { original silver } \\
& \Delta b^{*}=b^{*} \text { clean silver }-b^{*} \text { original silver }
\end{aligned}
$$

On the other hand the re-tarnishing effect was evaluated by the change of lightness value after each tarnishing cycle:

$$
\Delta L_{\mathrm{T}}=L^{*} \text { tarnished silver }-L^{*} \text { clean silver }
$$

Scanning electron micrographs (SEM) were obtained using the secondary electrons detector of a Hitachi S-4800 microscope, equipped with a cold-cathode field emission electron gun and an Oxford INCA system for energy dispersive X-ray spectrometry microanalysis (EDX).

XPS spectra were recorded using a Fisons MT500 spectrometer fitted with a hemispherical electron analyser (CLAM2) and a non-monochromatic $\mathrm{Mg} \mathrm{K \alpha} \mathrm{X}$-Ray source operated at $300 \mathrm{~W}(1253.6 \mathrm{eV})$. The samples were fixed on small flat discs supported on an XYZ manipulator placed in the analysis chamber. The residual pressure in this ion-pumped analysis chamber was maintained below $10^{-9}$ Torr during data acquisition. The spectra were recorded at take-off angles of $90^{\circ}$ and pass energy of $20 \mathrm{eV}$, which is typical of high-resolution conditions. The intensities were estimated by calculating the area under each peak after subtraction of the S-shaped background and fitting the experimental curve to a combination of Lorentzian and Gaussian fits of variable proportions. Although specimen charging was observed, it was possible to determine accurate binding energies $(B E)$ by referencing to the adventitious $\mathrm{C} 1 \mathrm{~s}$ peak at $285.0 \mathrm{eV}$ with accuracy to $\pm 0.2 \mathrm{eV}$. The atomic ratios were computed from the peak intensity ratios 
and the reported atomic sensitivity factors [39]. Laser cleaning efficiency (\%) was calculated by:

$$
\text { Laser cleaning efficiency }(\%)=\left(1-\frac{\% S_{\text {clean silver }}}{\% S_{\text {tarnished silver }}}\right) \times 100
$$

where $\% \mathrm{~S}$ denotes the atomic percentage of $\mathrm{S}^{2-}, \mathrm{S}-\mathrm{S}$ and $\mathrm{SO}_{4}{ }^{2-}$ peaks, analyzed by XPS. Analysis by micro-Raman spectroscopy was carried out with a Renishaw InVia 0310-02 system, equipped with a Leica microscope, and an electrically refrigerated chargecoupled device (CCD) camera. The excitation source was a diode laser operating at $785 \mathrm{~nm}$. Low laser powers of $3 \mathrm{~mW}$ were used to avoid damage of the analyzed material. Spectral acquisition was performed at room temperature using a focused beam on a randomly oriented sample. The diameter of the laser spot on the sample was diffraction limited by the objective ( $\times 50)$ lens and calculated to be $2 \mu \mathrm{m}$. The depth of the Raman probe was nominally $5 \mu \mathrm{m}$, although the depth reached could be influenced by the optical properties of the coupons and tarnish layers at the given laser excitation wavelength. For each spectrum, two scans were collected and summed up over the 100-1000 $\mathrm{cm}^{-1}$ Raman shift range to provide good signal to noise ratios. The wavenumber resolution and acquisition time are $2 \mathrm{~cm}^{-1}$ and $10 \mathrm{~s}$ respectively.

\section{Results}

\subsection{Mass variation}

The ideal cleaning procedure should be able to remove the tarnish layers without causing the loss of a significant amount of the base metal. Nevertheless, it was observed that the laser cleaning treatments applied in this work induced a progressive mass depletion. We consider that the mass loss is attributed to the effect of laser irradiation on the silver based samples and not to a variation of the tarnish coating. The latter could not be measured (as mentioned in sub-section 2.3) because it is within the error limit of the balance.

Pure silver was found especially vulnerable to laser treatment because all coupons experienced mass depletion after two or more cleaning cycles (Fig. 1 a). Laser irradiation at 1064 and $532 \mathrm{~nm}$ induced the highest loss of material by removal of over $3 \mathrm{mg} / \mathrm{cm}^{2}$ of the base metal after applying six tarnishing-laser cleaning cycles. Laser irradiation at 266 $\mathrm{nm}$ removed around $0.6 \mathrm{mg} / \mathrm{cm}^{2}$ for the same number of cycles (Fig. 1 a). Sterling silver was less vulnerable to laser cleaning according to the gravimetric measurements shown in Fig. 1 b. In this case, the mass variation was negligible for laser irradiation at 532 and 
$266 \mathrm{~nm}$, whereas for $1064 \mathrm{~nm}$ a loss of $2 \mathrm{mg} / \mathrm{cm}^{2}$ was induced after six tarnishing-laser cleaning cycles.
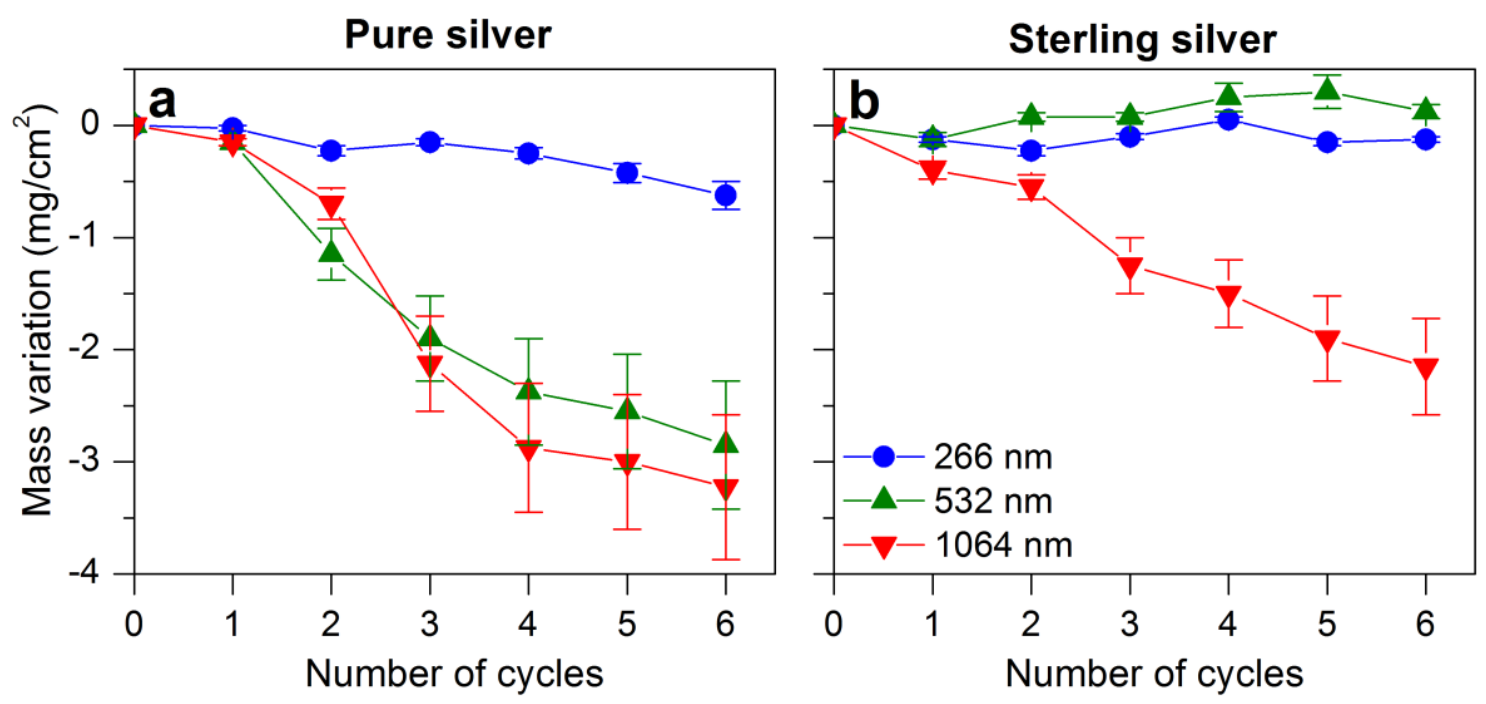

Fig. 1. Mass variation as a function of the number of tarnishing-laser cleaning cycles for a) pure and, b) sterling silver coupons at different laser wavelengths.

\subsection{Morphological surface characterization}

Pure and sterling silver coupons were examined by SEM after the first and sixth tarnishing-laser cleaning treatments to characterize the changes induced by laser irradiation upon cyclic tarnishing-laser cleaning treatments (Figs. 2 and 3).

Concerning the pure silver coupons, the first tarnishing-laser cleaning treatment caused the removal of most of the tarnish layer and the surface appeared partially melted with signs of scattered debris (Fig. 2 a-c). After the sixth tarnishing-laser cleaning treatment, superficial alteration was observed at the three laser wavelengths used (Fig. 2 d-f). The surface of the coupons cleaned at $266 \mathrm{~nm}$ presented the most irregular morphology, while the surface treated at 1064 and $532 \mathrm{~nm}$ displayed a more homogeneous appearance. 

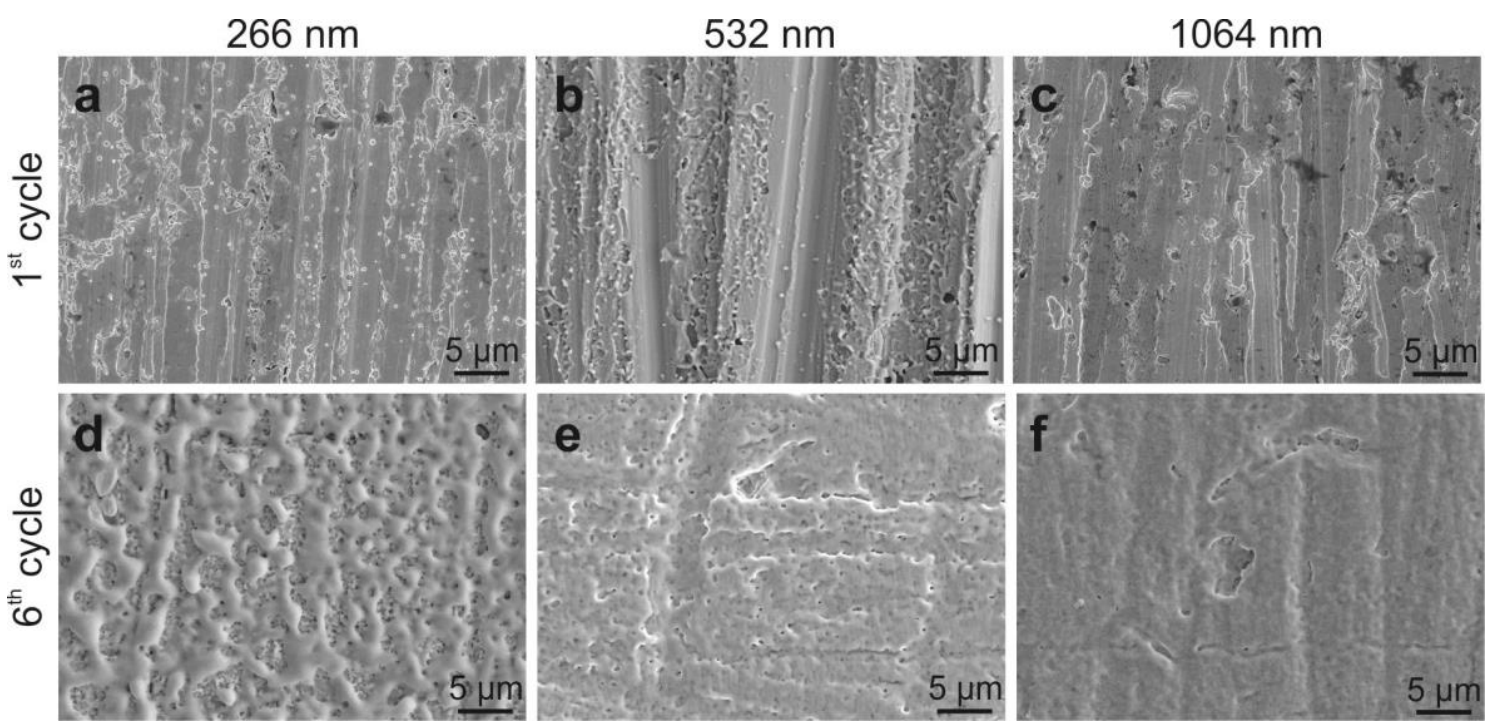

Fig. 2. SEM images of pure silver coupons after the first $(a, b, c)$ and the sixth $(d, e, f)$ tarnishing-laser cleaning cycles at the three indicated wavelengths.

However in the case of sterling silver, after the first tarnishing-laser cleaning treatment, regardless of the wavelength used, the surface of the coupons remained unaltered with the exception of some melting in localized areas (Fig. 3 a-c). After the sixth tarnishinglaser cleaning treatment small holes of about $1 \mu \mathrm{m}$ diameter were observed to cover the treated area (Fig. 3 d-f).

In all, it was observed that the sterling silver coupons were less altered by repetitive tarnishing-laser cleaning cycles than the pure silver ones. Both pure and sterling silver coupons treated at $1064 \mathrm{~nm}$ showed isolated and irregular cavities.
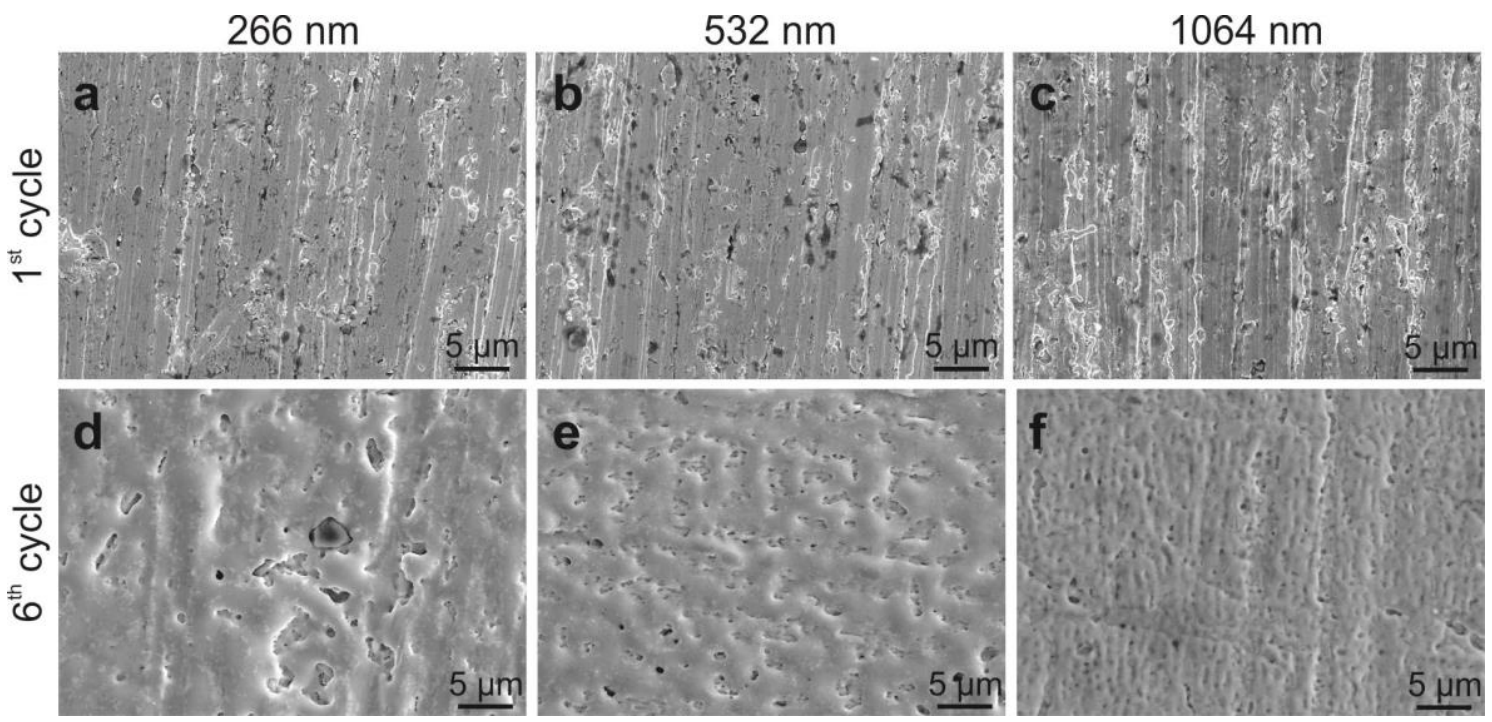

Fig. 3. SEM images of sterling silver coupons after the first $(a, b, c)$ and the sixth $(d, e, f)$ tarnishing-laser cleaning at the three indicated wavelengths. 


\subsection{Color variation}

Color change is a relevant parameter to consider when dealing with heritage silver artifacts, since changes in their visual appearance motivates restoration treatments in more extent than mass loss or changes in structural properties induced by corrosion phenomena. To quantify the color changes after each tarnishing-laser cleaning cycle, colorimetric measurements were performed on the original and laser cleaned coupons (Fig. 4 a-d). Laser treatment at 532 and $266 \mathrm{~nm}$ of pure silver coupons induces an inhomogeneous (as seen in large error bars) shift of color towards red $\left(\Delta a^{*}>0\right)$ (Fig. 4 a) and towards blue upon irradiation at $1064 \mathrm{~nm}\left(\Delta a^{*}\right.$ and $\left.\Delta b^{*}<0\right)$ (Fig. 4b). For the sterling silver coupons, laser irradiation at 532 and $266 \mathrm{~nm}$ does not significantly discolor the substrate (Fig. 4 c), while irradiation at 1064 nm leads to a shift towards blue (Fig. 4 c, d).
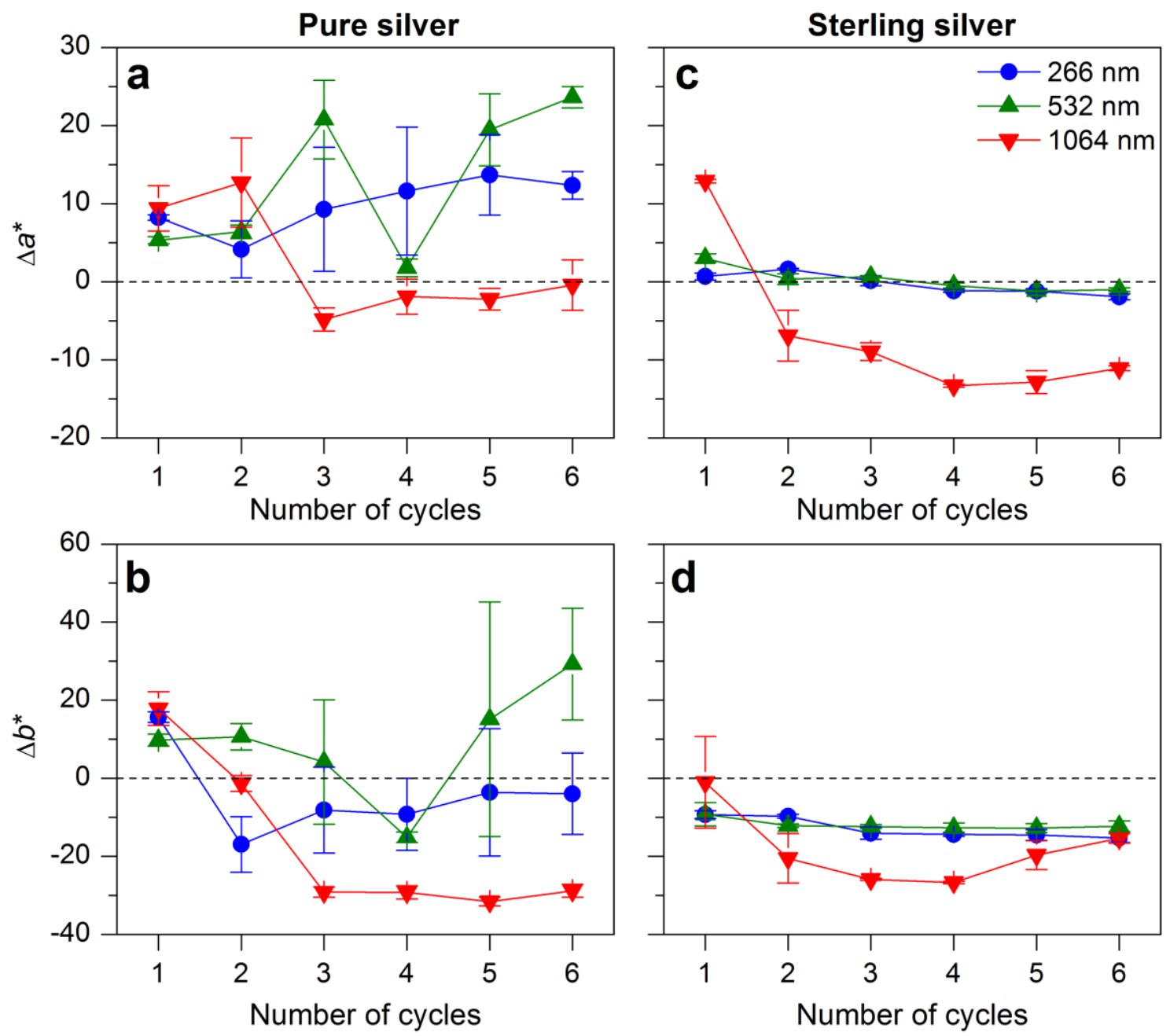

Fig. 4. Variation of $\Delta a *$ and $\Delta b *$ chromatic coordinates after tarnishing-laser cleaning treatments for a), b) pure, and c), d) sterling silver. 
After repetitive tarnishing-laser cleaning cycles the gaseous sulfur compounds react differently with the silver coupons inducing changes in their luminosity. Hence, measurements of luminosity served to evaluate the re-tarnishing rate. Higher re-tarnishing was observed after the first tarnishing-laser cleaning cycle, both for pure and sterling silver coupons (Fig. 5 a, b). However, this effect decreases after the second treatment and tends to zero upon laser irradiation at 532 and $266 \mathrm{~nm}$ for sterling silver (Fig. $5 \mathrm{~b}$ ), thus indicating a high stability of this material after laser cleaning at the mentioned laser wavelengths.
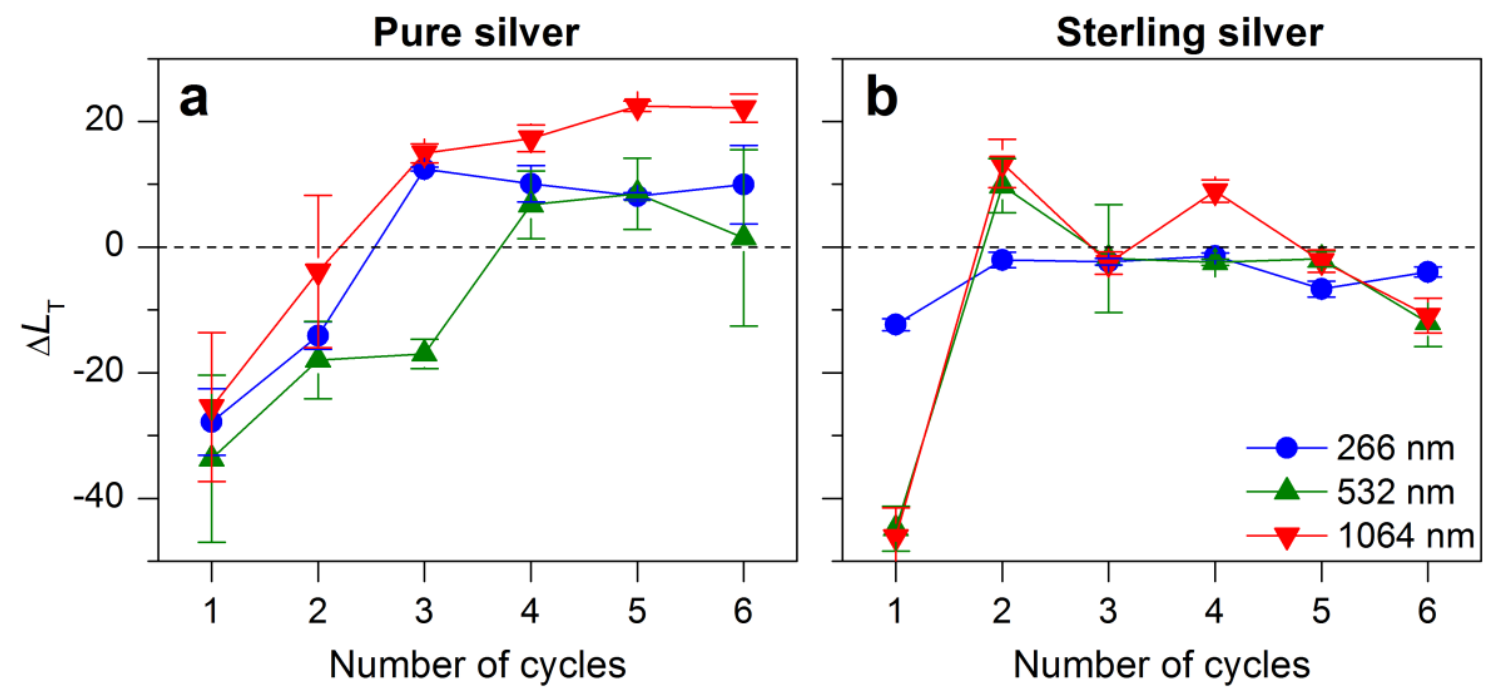

Fig. 5. Changes of luminosity $\left(\Delta L_{\mathrm{T}}\right)$ (Equation 5) as a function of the number of tarnishing-laser cleaning cycles for a) pure silver and b) sterling silver.

\subsection{X-ray Photoelectron Spectroscopy}

The XPS spectra of tarnished pure silver coupons showed the presence of carbon, oxygen, silver and sulfur; additionally copper was observed for tarnished sterling silver coupons. For pure silver coupons, the high resolution spectrum of $\mathrm{Ag} 3 \mathrm{~d}$ was fitted with a doublet (1.2 eV FWMH) at the $B E$ values of $368.2 \mathrm{eV}$ for the $3 \mathrm{~d}_{5 / 2}$ peak and $374.1 \mathrm{eV}$ for the $3 \mathrm{~d}_{3 / 2}$ one (Fig. 6 a). These peaks can be attributed to $\mathrm{Ag}, \mathrm{Ag}_{2} \mathrm{~S}$ and/or $\mathrm{Ag}_{2} \mathrm{O}$, although they cannot be resolved because of their similar binding energies (368.2, 368.1 and $367.9 \mathrm{eV}$, respectively) [40, 41]. AgO peaks were also observed at lower $B E$ values $(367.4 \mathrm{eV})$, although the peaks appeared overlapped with satellite peaks from secondary $\left(K_{\alpha 3}\right.$ and $\left.K_{\alpha 4}\right)$ emissions from the Mg X-ray anode. On the other hand, the $\mathrm{S} 2 \mathrm{p}$ spectrum showed a single doublet fitted by two peaks at $B E$ values of $161.4 \mathrm{eV}$ and $162.6 \mathrm{eV}$ (Fig. $6 \mathrm{~b}$ ). They 
correspond to $2 \mathrm{p}_{3 / 2}$ and $2 \mathrm{p}_{1 / 2}$ components, respectively and are attributed to sulfide compounds [42]. The doublet observed at $B E$ values of 168.64 and 169.84 eV (Fig. 6 b) can be assigned to sulfur species bonded to oxygen atoms, such as $\mathrm{SO}_{4}{ }^{2-}$. Silver coupons cleaned at $1064 \mathrm{~nm}$, and after the first tarnish cycle, presented another doublet peak assigned to S-S (BE values of 163.18 and $164.38 \mathrm{eV})$.

The XPS spectrum of sterling silver showed the presence of peaks attributed to copper species in addition to those observed in the case of pure silver. The XPS spectrum of $\mathrm{Cu}$ $2 p$ contains two peaks at $932.6 \mathrm{eV}$ and $952.1 \mathrm{eV}$ (Fig. 6 e), corresponding to $\mathrm{Cu} 2 \mathrm{p}_{3 / 2}$ and $\mathrm{Cu} 2 \mathrm{p}_{1 / 2}$, respectively and are characteristic of metallic $\mathrm{Cu}(0)$ and/or single ionized $\mathrm{Cu}$ (I). In order to obtain more details on the oxidation state of copper, the $\mathrm{Cu} \mathrm{L}_{3} \mathrm{M}_{45} \mathrm{M}_{45}$ Auger peak (Fig. 6 f) was analyzed. The calculation of the modified Auger parameter ( $\left.\alpha^{\prime}\right)$ was carried out according to equation 7 below, where $B E_{\mathrm{p}}$ is the binding energy of the photoelectron peak $(932.6 \mathrm{eV}), B E_{\mathrm{a}}$ is the apparent binding energy of the Auger peak $(916.63 \mathrm{eV})$, and $\mathrm{h} \theta$ is the $\mathrm{X}$-ray energy.

$$
\alpha^{\prime}=B E_{\mathrm{p}}+\left(\mathrm{h} \theta-B E_{\mathrm{a}}\right)
$$

The value of $\alpha$ ' was estimated in $1849.2 \mathrm{eV}$, indicating the presence of the single ionized $\mathrm{Cu}$ (I). On the other hand, the obtained $B E$ values and modified Auger parameter do not allow to distinguish between $\mathrm{Cu}_{2} \mathrm{O}$ and $\mathrm{Cu}_{2} \mathrm{~S}$ [40]. Before laser treatment the tarnished sterling silver coupons also present a single peak at a $B E$ value of $934.98 \mathrm{eV}$ which can be attributed to $\mathrm{Cu}^{2+}$ species (Fig. 6 e). 

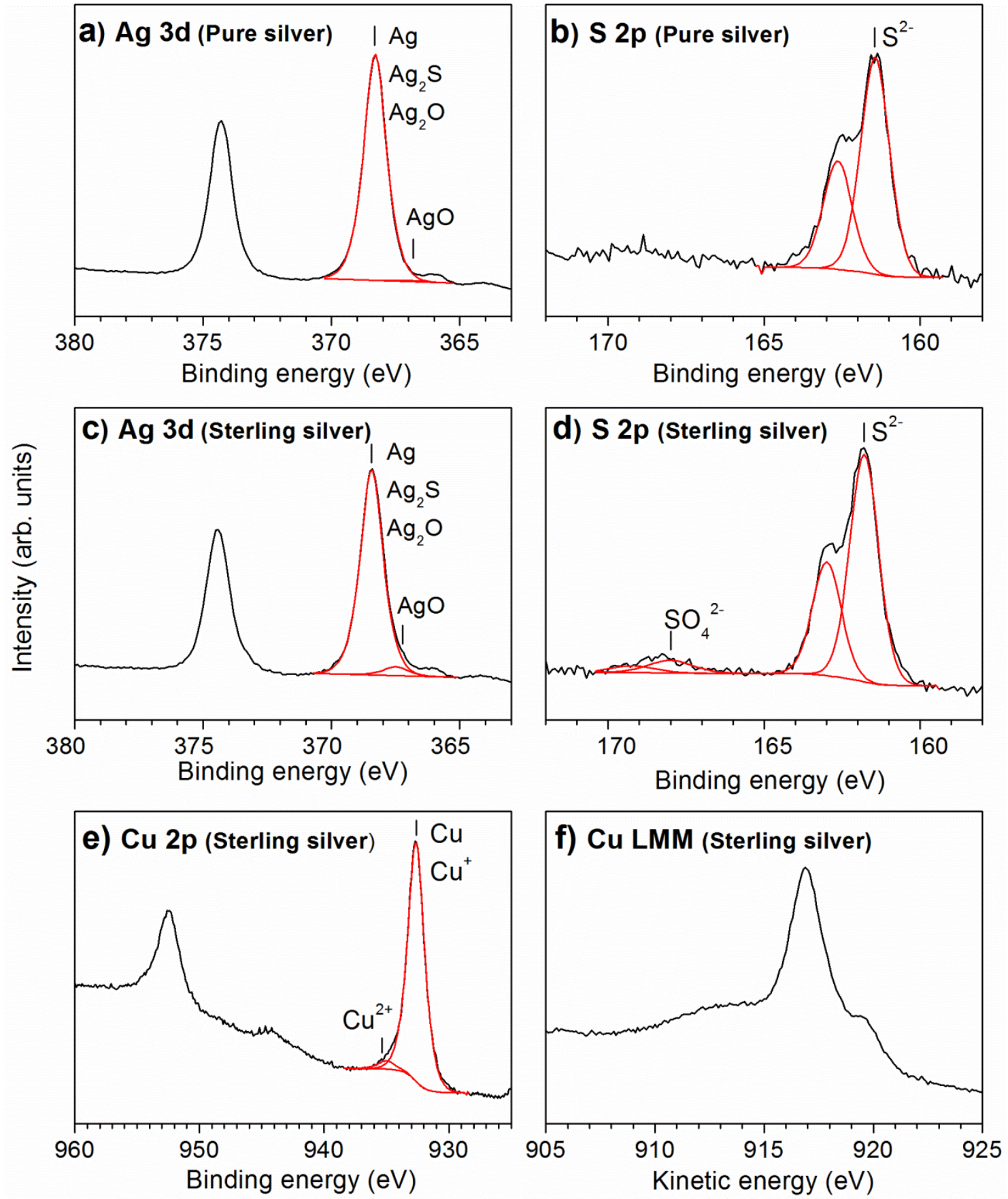

Fig. 6. High resolution XPS spectra on tarnished coupons before cleaning. a) $\mathrm{Ag} 3 \mathrm{~d}$ and b) S 2p for pure silver; c) Ag 3d, d) S 2p, e) Cu 2p and f) Cu Auger LMM for sterling silver.

In order to assess the surface alteration and laser cleaning efficiency, the atomic percentage of each observed element was calculated from the XPS spectra after tarnishing and after the first and the sixth tarnishing-laser cleaning cycles (Table 2). For pure silver before cleaning, the $\mathrm{Ag} / \mathrm{S}$ ratio is $2.3: 1$, very close to the stoichiometry of the $\mathrm{Ag}_{2} \mathrm{~S}$, indicating that, in the outermost layer analyzed by XPS, the Ag peak at $368.2 \mathrm{eV}$ can be attributed to silver sulfides. On the other side, the $\mathrm{Ag} / \mathrm{Cu} / \mathrm{S}$ ratios in the sterling silver 
(0.8:1.1:1) show a mixed composition of copper and silver sulfides. In pure silver coupons, the laser treatments at 1064 and $532 \mathrm{~nm}$ induced a decrease of sulfide content, especially after the first tarnishing-laser cleaning cycle (Table 2). For two of the treated pure silver coupons other sulfur species are present on their surface. In fact, after the first laser cleaning treatment at $1064 \mathrm{~nm}$ a 0.70 at. \% of S-S was measured, while after the sixth tarnishing-laser cleaning cycle at $266 \mathrm{~nm}$ the measured value of $\mathrm{SO}_{4}{ }^{2-}$ was 1.36 at. $\%$.

Regarding sterling silver, the sulfide content decreased as a function of the number of tarnishing-laser cleaning cycles. On the other hand, at 1064 and $532 \mathrm{~nm}$ the content of $\mathrm{S}^{2-}$ slightly decreased after the first cycle, and down to $\sim 5$ at. $\%$ after the sixth cycle. At 266 $\mathrm{nm}$ the $\mathrm{S}^{2-}$ content decreased to $\sim 8$ at. \% (Table 2). Moreover, after the first cycle, the coupons treated at $1064 \mathrm{~nm}$ showed the appearance of 0.37 at. \% of S-S based species. The content of copper $\left(\mathrm{Cu}^{0}, \mathrm{Cu}^{+}\right)$decreased considerably after the sixth cycle, independently of the laser wavelength.

Table 2. XPS compositional analysis on pure and sterling silver samples as a function of the laser wavelength and the number of cycles (at. \%).

\begin{tabular}{|c|c|c|c|c|c|c|c|c|c|}
\hline & & & \multirow{2}{*}{$\begin{array}{l}\text { Without } \\
\text { cleaning } \\
\text { (tarnished) }\end{array}$} & \multicolumn{2}{|c|}{$1064 \mathrm{~nm}$} & \multicolumn{2}{|c|}{$532 \mathrm{~nm}$} & \multicolumn{2}{|c|}{$266 \mathrm{~nm}$} \\
\hline & & & & $\begin{array}{l}1 \text { st } \\
\text { cycle }\end{array}$ & $\begin{array}{l}\text { 6th } \\
\text { cycle }\end{array}$ & $\begin{array}{l}1 \mathrm{st} \\
\text { cycle }\end{array}$ & $\begin{array}{l}\text { 6th } \\
\text { cycle }\end{array}$ & $\begin{array}{l}1 \mathrm{st} \\
\text { cycle }\end{array}$ & $\begin{array}{l}\text { 6th } \\
\text { cycle }\end{array}$ \\
\hline \multirow[t]{5}{*}{ Pure silver } & $\operatorname{Ag} 3 d$ & $\begin{array}{l}\mathrm{Ag}, \\
\mathrm{Ag}_{2} \mathrm{~S}, \\
\mathrm{Ag}_{2} \mathrm{O}\end{array}$ & 22.81 & 12.55 & 19.41 & 12.29 & 16.73 & 20.19 & 20.20 \\
\hline & & $\mathrm{AgO}$ & 0.11 & 0.08 & 0.32 & - & 0.13 & 0.22 & 0.31 \\
\hline & $\mathrm{S} 2 \mathrm{p}$ & $\mathrm{S}^{2-}$ & 9.81 & 4.06 & 8.67 & 3.76 & 7.61 & 6.24 & 8.96 \\
\hline & & S-S & - & 0.70 & - & - & - & - & - \\
\hline & & $\mathrm{SO}_{4}^{2-}$ & - & - & - & - & - & - & 1.36 \\
\hline \multirow[t]{7}{*}{$\begin{array}{l}\text { Sterling } \\
\text { silver }\end{array}$} & $\operatorname{Ag} 3 d$ & $\begin{array}{l}\mathrm{Ag}, \\
\mathrm{Ag}_{2} \mathrm{~S}, \\
\mathrm{Ag}_{2} \mathrm{O}\end{array}$ & 9.72 & 6.25 & 7.11 & 5.45 & 7.55 & 9.64 & 10.55 \\
\hline & & $\mathrm{AgO}$ & 0.44 & 0.09 & 0.11 & 0.09 & 0.06 & 0.25 & 0.12 \\
\hline & $\mathrm{S} 2 \mathrm{p}$ & $\mathrm{S}^{2-}$ & 11.92 & 9.66 & 5.69 & 7.09 & 5.40 & 11.71 & 8.14 \\
\hline & & S-S & - & 0.37 & - & - & - & - & - \\
\hline & & $\mathrm{SO}_{4}^{2-}$ & 1.05 & - & - & - & - & - & - \\
\hline & $\mathrm{Cu} 2 \mathrm{p}$ & $\mathrm{Cu}^{0}, \mathrm{Cu}^{+}$ & 12.52 & 13.51 & 9.08 & 6.18 & 2.99 & 13.98 & 6.12 \\
\hline & & $\mathrm{Cu}^{2+}$ & 0.44 & - & - & - & - & - & - \\
\hline
\end{tabular}

An ideal cleaning treatment should remove all traces of sulfur based species on the surface. The laser cleaning efficiency was calculated according to equation 6 by measuring the percentage of the removed sulfur based species $\left(\mathrm{S}^{2-}, \mathrm{S}-\mathrm{S}\right.$ and $\left.\mathrm{SO}_{4}{ }^{2-}\right)$ as a 
function of the laser wavelength and the number of the tarnishing-laser cleaning cycles. The obtained results are presented in Table 3, where it is observed that laser cleaning induces the partial removal of the sulfur based components in the tarnish layers on both pure and sterling silver coupons.

Table 3. Laser cleaning efficiency (\%) (Equation 6) on pure and sterling silver samples as a function of the number of cycles and the laser irradiation wavelength.

\begin{tabular}{lccc}
\hline & & \multicolumn{3}{c}{ Cleaning efficiency $(\%)$} \\
& Laser wavelength $(\mathrm{nm})$ & $1^{\text {st }}$ cycle & $6^{\text {th }}$ cycle \\
\hline Pure silver & 1064 & 52 & 12 \\
& 532 & 62 & 23 \\
Sterling silver & 266 & 36 & -5 \\
& 1064 & 23 & 56 \\
& 532 & 45 & 58 \\
& 266 & 10 & 37 \\
\hline
\end{tabular}

On pure silver coupons, the laser cleaning efficiency decreases with the cumulative cycles at the three considered wavelengths. Furthermore, at $266 \mathrm{~nm}$, the sulfur content after the sixth tarnishing-laser cleaning cycle was higher than the corresponding to the non treated sample (Table 2). This is due to the formation of more sulfur based species (sulfates), in addition to the tarnish layer remains.

Regarding the sterling silver coupons, the cleaning efficiency increases with the number of tarnishing-laser cleaning cycles. The samples cleaned at 1064 and $532 \mathrm{~nm}$ presented the highest cleaning efficiency after the sixth cycle of tarnishing-laser cleaning treatments (Table 3).

\subsection{Micro-Raman Spectroscopy}

The micro-Raman spectrum of untarnished silver coupons (Fig. 7 a, b) consist of a broad band around $230 \mathrm{~cm}^{-1}$ which is assigned to the stretching bending modes of silver oxide $\left(\mathrm{Ag}_{2} \mathrm{O}\right)[43,44]$. The presence of this compound testifies the high tendency of silver to oxidation under ambient conditions. Laser irradiation of pure silver coupons at 532 and $266 \mathrm{~nm}$ induces a decrease of intensity of the $\mathrm{Ag}_{2} \mathrm{O}$ band, while a shoulder around 200 $\mathrm{cm}^{-1}$, due to Ag lattice vibrational modes (i.e. phonons), increases. However, irradiation at $1064 \mathrm{~nm}$ leads to a higher oxide content, as revealed by the increase of intensity of the related band. Concerning sterling silver, irradiation at the three wavelengths induces a 
decrease of intensity of the $\mathrm{Ag}_{2} \mathrm{O}$ band, indicating a similar removal rate of the $\mathrm{Ag}_{2} \mathrm{O}$ layer.

For pure silver, the first tarnishing-laser cleaning cycle (Fig. $7 \mathrm{c}$ ) results in the appearance of a couple of bands at 185 and $237 \mathrm{~cm}^{-1}$ that are assigned to the Ag-S stretching and bending vibrations modes of $\mathrm{Ag}_{2} \mathrm{~S}$, respectively [43, 44]. At $1064 \mathrm{~nm}$, the Raman spectra reveal slight differences in the intensity of the $\mathrm{Ag}_{2} \mathrm{~S}$ bands. However, irradiation at 532 and $266 \mathrm{~nm}$ leads to an appreciable decrease of their intensity, compatible with the efficient removal of the tarnish layer. The micro-Raman spectra of tarnished sterling silver coupons (Fig. 7 d) differ markedly from those of pure silver. In this case, a broad band around $242 \mathrm{~cm}^{-1}$ was observed. Independently of the wavelength used this band widens and shifts to $250 \mathrm{~cm}^{-1}$.

After six tarnishing-laser cleaning cycles the micro-Raman spectra of pure and sterling silver coupons showed different behaviors (Fig. 7 e, f). For pure silver, an extra band at $463 \mathrm{~cm}^{-1}$, with a shoulder at $473 \mathrm{~cm}^{-1}$ (Fig. 7 e), is observed. The band at $463 \mathrm{~cm}^{-1}$ is assigned to the $\mathrm{O}-\mathrm{S}-\mathrm{O}$ bending vibration. As the absence of bands at 964 or $970 \mathrm{~cm}^{-1}$ rules out the presence of $\mathrm{Ag}_{2} \mathrm{SO}_{3}$ and $\mathrm{Ag}_{2} \mathrm{SO}_{4}$ compounds respectively [44], it is possible to assign the vibration at $463 \mathrm{~cm}^{-1}$ to cluster species composed of sulfur and oxygen atoms. The shoulder at $473 \mathrm{~cm}^{-1}$ corresponds to the vibrational modes of the $\mathrm{S}-\mathrm{S}$ bond of $\mathrm{S}_{8}$ (with orthorhombic crystal structure) [8, 45]. These bands at 463 and $473 \mathrm{~cm}^{-1}$ appear upon laser irradiation at 1064 and $266 \mathrm{~nm}$ (with higher intensity upon irradiation at $1064 \mathrm{~nm}$ ). Besides, bands at 185 and $237 \mathrm{~cm}^{-1}$, due to $\mathrm{Ag}_{2} \mathrm{~S}$, remain present after the first tarnishinglaser cleaning cycle. This indicates that irradiation at 1064 and $266 \mathrm{~nm}$ fails to completely remove the superficial $\mathrm{Ag}_{2} \mathrm{~S}$; on the contrary, even more $\mathrm{Ag}_{2} \mathrm{~S}$ is formed, in accordance with the XPS results. Treatment at $532 \mathrm{~nm}$ using six tarnishing-laser cleaning cycles induces similar effects than those described for irradiation at 1064 and $266 \mathrm{~nm}$, although in a less extent for the shoulder at $473 \mathrm{~cm}^{-1}$ and the significant decrease of intensity of $\mathrm{Ag}_{2} \mathrm{~S}$ bands at 183 and $240 \mathrm{~cm}^{-1}$. According to these results, it seems that none of the irradiation treatments applied to the pure silver coupons is effective for the removal of the artificial tarnish layer.

For sterling silver, the micro-Raman spectra acquired after the sixth tarnishing-laser cleaning cycle at 1064, 532 and $266 \mathrm{~nm}$ were markedly different (Fig. 7 f). At $1064 \mathrm{~nm}$ the broad band around $468 \mathrm{~cm}^{-1}$, attributed to the $\mathrm{S}-\mathrm{O}$ bending vibration of cluster species containing sulfur and oxygen and to the vibration of the $\mathrm{S}-\mathrm{S}$ bond of $\mathrm{S}_{8}$, appears very weak. However the intensity of the band around $250 \mathrm{~cm}^{-1}$, related to $\mathrm{Ag}_{2} \mathrm{~S}$, increases. 
Laser treatment at $266 \mathrm{~nm}$ significantly reduces the amount of the main component of the artificial tarnish layer on sterling silver coupons. Together with the decrease of intensity of the band around $250 \mathrm{~cm}^{-1}$, a couple of weak bands at 164 and $314 \mathrm{~cm}^{-1}$ were observed, due to the presence of metallic $\mathrm{Cu}$ and $\mathrm{Cu}_{2} \mathrm{O}[46,47]$. The effects observed at $266 \mathrm{~nm}$ were more noticeable upon laser treatment at $532 \mathrm{~nm}$.

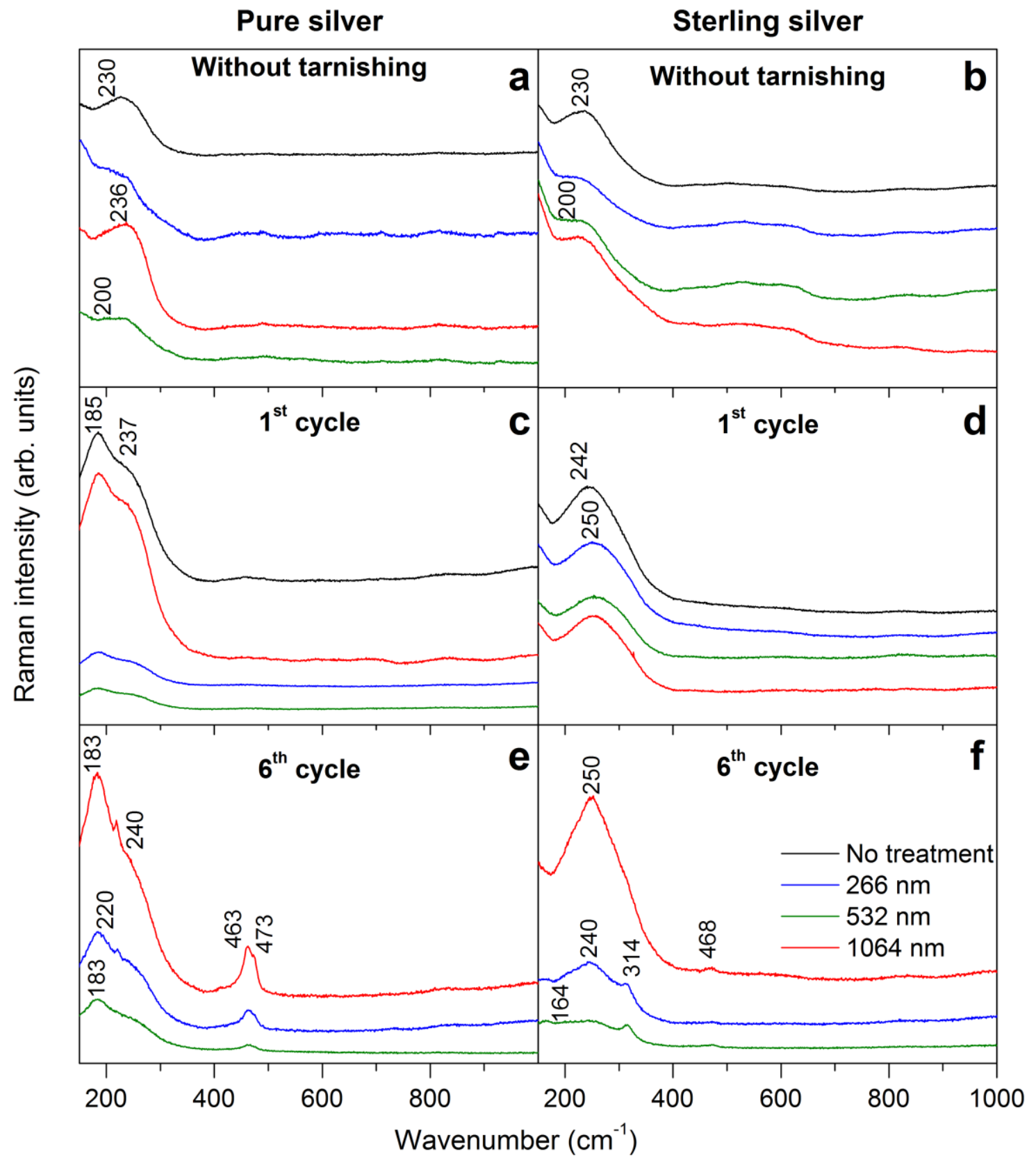

Fig. 7. Micro-Raman spectra of bare and artificially tarnished silver and sterling silver coupons upon laser irradiation at 266, 532 and $1064 \mathrm{~nm}$, a) pure silver, b) pure sterling silver, c) and d) after the first tarnishinglaser cleaning cycle ,e) and f) after the sixth tarnishing-laser cleaning cycle.

\section{Discussion}


Examination of the pure and sterling silver coupons after repetitive tarnishing-laser cleaning cycles has shown that the treatments induce different degrees of chemical and physical changes depending on the laser wavelength. These changes are summarized in Table 4.

Table 4. Summary of the results obtained after six tarnishing-laser cleaning cycles of pure and sterling silver coupons at three laser wavelengths.

\begin{tabular}{|c|c|c|c|c|c|c|c|}
\hline & $\lambda(\mathrm{nm})$ & $\begin{array}{l}\text { Mass } \\
\text { variation }\end{array}$ & $\begin{array}{l}\text { Color } \\
\text { variation }\end{array}$ & Re-tarnishing & Microstructure & $\begin{array}{l}\text { Chemical } \\
\text { changes (XPS, } \\
\mu \text {-Raman) }\end{array}$ & $\begin{array}{l}\text { Cleaning } \\
\text { efficiency }\end{array}$ \\
\hline \multirow[t]{3}{*}{ Pure silver } & 1064 & High & High & Variable & $\begin{array}{l}\text { Alteration } \\
\text { layer }\end{array}$ & Intense & $<25 \%$ \\
\hline & 532 & High & High & Variable & $\begin{array}{l}\text { Alteration } \\
\text { layer }\end{array}$ & Moderate & $<25 \%$ \\
\hline & 266 & Moderate & High & Variable & $\begin{array}{l}\text { Alteration } \\
\text { layer }\end{array}$ & Moderate & $<25 \%$ \\
\hline \multirow[t]{3}{*}{$\begin{array}{l}\text { Sterling } \\
\text { silver }\end{array}$} & 1064 & High & High & Variable & $\begin{array}{l}\text { Alteration } \\
\text { layer }\end{array}$ & Intense & $>50 \%$ \\
\hline & 532 & Low & Low & Low & $\begin{array}{l}\text { Alteration } \\
\text { layer }\end{array}$ & Low & $>50 \%$ \\
\hline & 266 & Low & Low & Low & $\begin{array}{l}\text { Alteration } \\
\text { layer }\end{array}$ & Moderate & $50 \%-25 \%$ \\
\hline
\end{tabular}

The results obtained give evidence that most of the tarnish layer is removed after the first laser cleaning cycle of the artificially tarnished samples. Melted material and remains of the tarnish layer were observed on the underlying surface in few zones of the irradiated coupons. In addition, after each tarnishing-laser cleaning cycle a progressive mass depletion was observed. Regardless of the irradiation laser wavelength an alteration layer was observed on the surface of the coupons after six tarnishing-laser cleaning cycles. According to XPS and micro-Raman measurements, this alteration layer still contains traces of sulfur compounds, principally $\mathrm{Ag}_{2} \mathrm{~S}$. In fact, the tarnish layer is ablated, or locally annealed and melted, by laser irradiation and partially re-deposits. Upon laser ablation two processes can participate in the material removal, with relative contributions depending on the irradiation wavelengths. The first one, of photo-thermal or/and photomechanical origin, should be favored using infrared wavelengths while the second one, of photo-chemical origin, prevails at visible and ultraviolet wavelengths. These two 
processes are followed by removal and partial re-deposition of the ablated/removed $\operatorname{Ag}_{2} \mathrm{~S}$ material.

Pure and sterling silver coupons treated at $1064 \mathrm{~nm}$ experience the highest mass loss. This suggest that photo-thermal effects, favored by infrared irradiation and the low value of the linear absorption coefficient of the tarnish layer in this spectral region [48], are responsible of the high vaporization of material and low re-deposition on the surface. Previous studies [29] have reported similar melting/vaporization effects on the surface of silver based materials by irradiation at $1064 \mathrm{~nm}$.

Besides the mass loss, color variation and chemical modifications were also observed in this study. In pure silver coupons, the laser cleaning treatment at 532 and $266 \mathrm{~nm}$ induced a shift of color towards red and a respective shift towards blue at $1064 \mathrm{~nm}$. In sterling silver, irradiation at $1064 \mathrm{~nm}$ induced a shift towards blue, while at 532 and $266 \mathrm{~nm}$, where the tarnish layers absorb better than at $1064 \mathrm{~nm}$ [48], the color of the coupons was not altered (see section 3.3.). Formation of particles has been reported to accompany laser cleaning of tarnished copper coins, tarnished silver threads and archaeological iron [28, 49]. It has been suggested that these effects are due to vaporization and re-deposition of the metal. The nature of the observed color changes is directly related to the thickness of the re-deposited layer created by repetitive cycles of laser ablation. However, previous studies $[16,50]$ did not report any surface alterations when cleaning copper alloys using a Nd:YAG laser at $1064 \mathrm{~nm}$ with pulse duration in the microsecond regime. The use of these longer pulses is expected to increase the conduction of heat to the bulk material as compared with nanosecond pulses. The sterling silver coupons cleaned at 532 and 266 $\mathrm{nm}$ showed a similar behavior after successive tarnishing-laser cleaning cycles, which is compatible with reduced extent of laser-induced effects. The accompanying decrease of luminosity after the first tarnishing-laser cleaning treatment is due to the presence of oxidized species. Similar darkening was observed on Roman copper coins [51], laser cleaned at 532 and $266 \mathrm{~nm}$, effect that was attributed to further oxidation of $\mathrm{Cu}_{2} \mathrm{O}$ to $\mathrm{CuO}$. However, in our case, XPS results (Table 2) do not show the formation of $\mathrm{Cu}^{2+}$ compounds, and the color change also occurs in pure silver samples. Thus this explanation can be disregarded and the darkening can be attributed to the presence of $\mathrm{Ag}_{2} \mathrm{~S}$.

Re-tarnishing effects were assessed by measuring the differences of luminosity of the coupons before and after tarnishing of previously laser cleaned coupons. After successive laser cleaning cycles, sulfur compounds react differently with pure and sterling silver. High re-tarnishing effects were observed for pure silver coupons, as shown by significant 
changes in surface luminosity upon exposure to the polluted environment. However, sterling silver coupons laser treated at 532 and $266 \mathrm{~nm}$ showed a slight variation of luminosity indicating a high stability of this material after repetitive cycles of treatment. A fast re-tarnishing effect was observed after mechanical and chemical cleaning of sterling silver substrates due to the high reactivity of cleaned surfaces to gaseous sulfur based species [12].

For pure silver coupons the cleaning efficiency after the first tarnishing-laser cleaning cycle (Table 3$)$ is better $(40-60 \%)$ than the corresponding to the sixth one $(-5-20 \%)$. The calculated negative value reveals the increase of sulfur components after laser treatment. For sterling silver coupons the opposite is observed, with higher cleaning efficiencies after cumulative laser treatments, with better results at the wavelengths of 1064 and $532 \mathrm{~nm}$.

XPS and micro-Raman analyses of the silver samples performed after successive laser cleaning treatments confirmed that the alteration layer is composed by cluster species of sulfur and oxygen and by re-deposited ablated $\mathrm{Ag}_{2} \mathrm{~S}$ material. This behavior was more noticeable on pure silver coupons and on the sterling silver ones treated at $1064 \mathrm{~nm}$. These effects are in agreement with the mass loss detected by gravimetry, the color variation monitored by colorimetry and the alteration layer observed by SEM. Similar results have been observed on silver threads in textiles after laser cleaning at $1064 \mathrm{~nm}$ [28]. Laser irradiation of sterling silver coupons at 532 and $266 \mathrm{~nm}$ have shown an improvement of cleaning efficiency by cumulative laser cleaning cycles. Treatment at $266 \mathrm{~nm}$ significantly reduces the tarnish layer efficiency on sterling silver coupons, although six laser cleaning treatments lead to the presence of metallic $\mathrm{Cu}$ and $\mathrm{Cu}_{2} \mathrm{O}$. Similar results were observed by Buccolieri et al. [33] upon $\mathrm{KrF}$ laser cleaning of sterling silver objects that lead to the formation of new species on the surface. Laser cleaning upon irradiation at $532 \mathrm{~nm}$ seems to be the most efficient procedure for removal of tarnish layers. Then, according to the XPS and micro-Raman results, the visible laser wavelength at $532 \mathrm{~nm}$ appears as the most appropriate for laser cleaning of sterling silver coupons.

\section{Conclusions}

The results presented lead to conclude that the cleaning efficiency of silver artifacts using ns pulses of a Nd:YAG laser depends on the specific composition of the substrate and on the irradiation wavelength. After repetitive tarnishing-laser cleaning cycles, artificially tarnished pure silver coupons were especially vulnerable to the laser treatment; they 
experienced a significant loss of mass accompanied with the formation of colored alteration layers. The most important alteration was caused by irradiation at $1064 \mathrm{~nm}$, which leads to the highest loss of mass and change of color towards a blue hue, due to the thermal effects induced by infrared irradiation. Sterling silver coupons maintained their mass and color upon repetitive laser cleaning treatments at 532 and $266 \mathrm{~nm}$. The retarnishing effect was significant for pure silver coupons for all considered wavelengths; however, it was barely observed on sterling silver treated at 532 and $266 \mathrm{~nm}$. XPS and micro-Raman spectroscopic measurements allowed the identification of the chemical species present on the silver coupons before and after laser irradiation. After repetitive laser cleaning cycles, pure silver coupons revealed the presence of an alteration layer with high content in sulfur-based deposits, developed on the surface due to ablation and redeposition of cluster species with S-S and O-S-O bonds. For sterling silver the content of these sulfur based species is negligible upon laser irradiation at 532 and $266 \mathrm{~nm}$, and these compounds were not observed after the first tarnishing-laser cleaning cycle. The alteration effects induced upon laser irradiation on the silver based coupons are less important after the first tarnishing-laser cleaning cycle than after the sixth one. In view of the results of this study, it can be concluded that Q-switched Nd:YAG laser cleaning is not recommended for pure silver historical objects, while for sterling silver artifacts, the visible laser wavelength at $532 \mathrm{~nm}$ seems to be the most appropriate.

\section{Acknowledgements}

The authors acknowledge P. Navarro for providing the 99 wt \% silver and O. García for colorimetric measurements. This work has been funded by project CREMEL (Ref. HAR2011-22402), by a pre-doctoral FPI grant (BES-2012-052716) from the Spanish Ministry of Economy and Competitiveness (MINECO), by program GEOMATERIALES 2-CM (Ref. CAM, S2013/MIT_2914) from the Community of Madrid, and by EU project "Integrated Platform for the European Research Infrastructure on Cultural Heritage" (IPERION-CH, Ref. H2020-INFRAIA-2014-2015, grant $n^{\circ}$ 654028). M.O. thanks CSIC for a contract. Finally, the authors want to mention the support of the Spanish Network on Science and Technology for the Conservation of Cultural Heritage (TechnoHeritage). 


\section{References}

[1] D. Lafuente, E. Cano, E. Martín, Indoor pollution and metal corrosion by organic acids: Case study of the Oteiza Museum (Spain), in: Science and Technology for the Conservation of Cultural Heritage, CRC Press, 2013, pp. 99-102.

[2] D. Lafuente, E. Cano, I. Llorente, A. Crespo, J. Künne, A. Schieweck, The effects of organic pollutants on metals in museums: Corrosion products, synergistic effects and the influence of climatic parameters, in: Metal 2013. Triennial conference of the International Council of Museums Committee for Conservation Metal Working Group (ICOM-CC Metal WG), $16^{\text {th }}-20^{\text {th }}$ September 2013, Edinburgh, Scotland, 2013.

[3] F. Faraldi, E. Angelini, A. Mezzi, C. Riccucci, T. de Caro, G. Di Carlo, Surface studies of environmental reactive species during exhibition or storage of ancient Ag-based artefacts, Surf Interface Anal, 46 (2014) 796-800.

[4] J.P. Franey, G.W. Kammlott, T.E. Graedel, The corrosion of silver by atmospheric sulfurous gases, Corros Sci, 25 (1985) 133-143.

[5] L.S. Selwyn, Historical silver: Storage, display, and tarnish removal, J Int Inst Conserv Hist Artistic Works, 15 (1990) 12-22.

[6] T. Graedel, Corrosion mechanisms for silver exposed to the atmosphere, J Electrochem Soc, 139 (1992) 1963-1970.

[7] V. Costa, The deterioration of silver alloys and some aspects of their conservation, Stud Conserv, 46 (2001) 18-34.

[8] G.M. Ingo, E. Angelini, C. Riccucci, T. de Caro, A. Mezzi, F. Faraldi, D. Caschera, C. Giuliani, G. Di Carlo, Indoor environmental corrosion of Ag-based alloys in the Egyptian Museum (Cairo, Egypt), Appl Surf Sci, 326 (2015) 222-235.

[9] R. Wiesinger, I. Martina, C. Kleber, M. Schreiner, Influence of relative humidity and ozone on atmospheric silver corrosion, Corros Sci, 77 (2013) 69-76.

[10] G. Wharton, S.L. Maish, W.S. Ginell, A comparative study of silver cleaning abrasives, J Am Inst Conserv, 29 (1990) 13-31.

[11] L.S. Selwyn, C.G. Costain, Evaluation of silver-cleaning products, J Int Inst ConservCanadian Group, 16 (1991) 3-16.

[12] T. Palomar, B. Ramírez Barat, E. García, E. Cano, A comparative study of cleaning methods for tarnished silver, J Cult Herit, 17 (2016) 20-26.

[13] J. Contreras-Vargas, J.L. Ruvalcaba-Sil, F.J. Rodríguez-Gómez, Effects of the cleaning of silver with acidified thiourea solutions, in: Conference proceedings of Metal 2013, Historic Scotland and International Council of Museums, Edinburgh, 2013, pp. 223-228.

[14] A. Kearns, C. Fischer, K. Watkins, M. Glasmacher, H. Kheyrandish, A. Brown, W. Steen, P. Beahan, Laser removal of oxides from a copper substrate using Q-switched Nd: YAG radiation at $1064 \mathrm{~nm}, 532 \mathrm{~nm}$ and $266 \mathrm{~nm}$, Appl surf sci, 127 (1998) 773-780.

[15] C. Cottam, D. Emmony, TEA-CO $\mathrm{CO}_{2}$ laser surface processing of corroded metals, Corros Sci, 41 (1999) 1529-1538.

[16] R. Pini, S. Siano, R. Salimbeni, M. Pasquinucci, M. Miccio, Tests of laser cleaning on archeological metal artefacts, J Cult Herit, 1, Supplement 1 (2000) S129-S137.

[17] S. Siano, R. Pini, R. Salimbeni, Coated bronze cleaning by Nd: YAG lasers, in: Lasers in Metrology and Art Conservation, International Society for Optics and Photonics, 2001, pp. 4245.

[18] Y. Koh, I. Sárady, Cleaning of corroded iron artefacts using pulsed TEA $\mathrm{CO}_{2}$-and Nd:YAGlasers, J Cult Herit, 4 (2003) 129-133.

[19] S. Siano, R. Salimbeni, R. Pini, A. Giusti, M. Matteini, Laser cleaning methodology for the preservation of the Porta del Paradiso by Lorenzo Ghiberti, J Cult Herit, 4, Supplement 1 (2003) 140-146. 
[20] E. Drakaki, A. Karydas, B. Klinkenberg, M. Kokkoris, A. Serafetinides, E. Stavrou, R. Vlastou, C. Zarkadas, Laser cleaning on Roman coins, Appl Phys A-Mater, 79 (2004) 1111-1115.

[21] P. Mottner, G. Wiedemann, G. Haber, W. Conrad, A. Gervais, Laser cleaning of metal surface-laboratory investigations, in: Proceedings of the International Conference LACONA V Lasers in the Conservation of Artworks, Springer, Osnabrueck, Germany, 2005, pp. 79-86.

[22] A. Siatou, D. Charalambous, V. Argyropoulos, P. Pouli, A comprehensive study for the laser cleaning of corrosion layers due to environmental pollution for metal objects of cultural value: preliminary studies on artificially corroded coupons, Laser Chem, 2006 (2006) 1-7.

[23] C. Korenberg, A. Baldwin, Laser cleaning tests on archaeological copper alloys using an ND: YAG Laser, Laser Chem, 2006 (2006) Article ID 75831.

[24] S. Siano, F. Grazzi, V.A. Parfenov, Laser cleaning of gilded bronze surfaces, J Opt Technol, 75 (2008) 419-427.

[25] S. Siano, R. Salimbeni, Advances in laser cleaning of artwork and objects of historical interest: The optimized pulse duration approach, Accounts Chem Res, 43 (2010) 739-750.

[26] A. Lorusso, V. Nassisi, A. Buccolieri, G. Buccolieri, A. Castellano, L.S. Leo, M. Di Giulio, L. Torrisi, F. Caridi, A. Borrielli, Laser ablation threshold of cultural heritage metals, Radiat Eff Defect S, 163 (2008) 325-329.

[27] P. Pouli, M. Oujja, M. Castillejo, Practical issues in laser cleaning of stone and painted artefacts: optimisation procedures and side effects, Appl. Phys. A, 106 (2012) 447-464.

[28] C. Degrigny, E. Tanguy, R. Le Gall, V. Zafiropulos, G. Marakis, Laser cleaning of tarnished silver and copper threads in museum textiles, J Cult Herit, 4 (2003) 152-156.

[29] J.M. Lee, J.E. Yu, Y.S. Koh, Experimental study on the effect of wavelength in the laser cleaning of silver threads, J Cult Herit, 4 (2003) 157-161.

[30] M. Pires, J. Faustino, T. Ferraz, K. Watkins, Laser cleaning of silver surfaces, in: Proceedings of the XVI International Symposium on Gas Flow, Chemical Lasers, and HighPower Lasers, International Society for Optics and Photonics, 2007, pp. 63461F-63467F. [31] A. Serafetinides, E. Drakaki, E. Fabrikesi, M. Kandyla, I. Zergioti, C. Vlachou-Mogire, R. Thomson, A. Kar, N. Boukos, A. Karydas, Comparative evaluation of ultrafast laser beam interaction with the silvering in late Roman coins, in: SPIE Europe Optical Metrology, International Society for Optics and Photonics, 2009, pp. Article ID 73910P.

[32] S. Kholodova, D. Goryachkin, L. Koval'chuk, S. Smirnov, The cleaning of works of art made from metal with laser radiation at wavelengths of 1.06 and $10.6 \mu \mathrm{m}$, J Opt Technol, 77 (2010) 303-308.

[33] A. Buccolieri, G. Buccolieri, A. Castellano, A. Lorusso, V. Nassisi, Experimental results of UV laser cleaning on a silver Carlino coin, Radiat Eff Defect S, 165 (2010) 643-651.

[34] E. Drakaki, B. Klingenberg, A.A. Serafetinides, E. Kontou, N. Katsikosta, P. Tselekas, D. Evgenidou, N. Boukos, A. Zanini, Evaluation of laser cleaning of ancient Greek, Roman and Byzantine coins, Surf Interface Anal, 42 (2010) 671-674.

[35] UNE-EN ISO 4538, Recubrimientos metálicos. Ensayo de corrosión a la tioacetamida (Ensayo TAA), in, 1996.

[36] ASTM D1729, Standard practice for visual appraisal of colors and color differences of diffusely-illuminated opaque materials, in, 2009.

[37] D. Malacara, Color vision and colorimetry: Theory and applications, SPIE Press, Bellingham, 2002.

[38] K. Minolta, Precise color communication: color control from perception to instrumentation, Konica Minolta Sensing INC., 2007

[39] C. Wagner, L. Davis, M. Zeller, J. Taylor, R. Raymond, L. Gale, Empirical atomic sensitivity factors for quantitative analysis by electron spectroscopy for chemical analysis, Surf Interface Anal, 3 (1981) 211-225.

[40] D. Briggs, M.P. Seah, Practical surface analysis: Auger and X-ray photoelectron spectroscopy. $2^{\text {nd }}$ edition, John Wiley\& Sons, 1990. 
[41] D.M. Bastidas, E. Cano, A.G. González, S. Fajardo, R. Lleras-Pérez, E. Campo-Montero, F.J. Belzunce-Varela, J.M. Bastidas, An XPS study of tarnishing of a gold mask from a pre-

Columbian culture, Corros Sci, 50 (2008) 1785-1788.

[42] Measurement Services Division of the National Institute of Standards and Technology (NIST), NIST Standard Reference Database 20, Version 4.1, URL:

http://srdata.nist.gov/xps/Default.aspx.

[43] I. Martina, R. Wiesinger, D. Jembrih-Simbürger, M. Schreiner, Micro Raman

characterization of silver corrosion products: instrumental set up and reference database, EPreservation Sci, 9 (2012) 1-8.

[44] I. Martina, R. Wiesinger, M. Schreiner, Micro-Raman investigations of early stage silver corrosion products occurring in sulfur containing atmospheres, J Raman Spectrosc, 44 (2013) 770-775.

[45] S.N. White, Laser Raman spectroscopy as a technique for identification of seafloor hydrothermal and cold seep minerals, Chem Geol, 259 (2009) 240-252.

[46] J. Trajić, R. Rudolf, I. Anžel, M. Romčević, N. Lazarević, M. Mirić, Z. Lazarević, B. Hadžić, N. Romčević, Optical properties of plastically deformed copper, Acta Phys Pol A, 117 (2010) 791793.

[47] Y. Mao, J. He, X. Sun, W. Li, X. Lu, J. Gan, Z. Liu, L. Gong, J. Chen, P. Liu, Electrochemical synthesis of hierarchical $\mathrm{Cu}_{2} \mathrm{O}$ stars with enhanced photoelectrochemical properties, Electrochim Acta, 62 (2012) 1-7.

[48] V. Krylova, L. Samoulaitiene, Investigation of optical and electrical properties of silver sulfide films deposited on polyamide substrates, Mat Sci, 19 (2013) 10-14.

[49] K. Dickmann, J. Hildenhagen, J. Studer, E. Müsch, Archaeological ironwork: Removal of corrosion layers by Nd:YAG-Laser, in: K. Dickmann, C. Fotakis, J. Asmus (Eds.) Lasers in the Conservation of Artworks, Springer Berlin Heidelberg, 2005, pp. 71-77.

[50] S. Batishche, A. Kouzmouk, H. Tatur, T. Gorovets, U. Pilipenka, V. Ukhau, 1320 nm range $\mathrm{Nd}$ :YAG-Laser in restoration of artworks made of bronze and other metals, in: K. Dickmann, C. Fotakis, J. Asmus (Eds.) Lasers in the Conservation of Artworks, Springer Berlin Heidelberg, 2005, pp. 87-93.

[51] C. Vlachou-Mogire, E. Drakaki, A. Serafetinides, I. Zergioti, N. Boukos, Experimental study on the effect of wavelength and fluence in the laser cleaning of silvering in late Roman coins (Mid $3^{\text {rd }} / 4^{\text {th }}$ century AD), in: 14 th International School on Quantum Electronics: Laser Physics and Applications, International Society for Optics and Photonics, 2007, pp. Article ID 66040W. 